\title{
A ESTRUTURA DIALÉtica DA POLÍTICA EM HENRIQUE CLÁUDIO DE LIMA VAZ
}

The dialectical structure of Politics in Henrique Cláudio de Lima Vaz

Manuel Moreira da Silva *

Resumo: Este trabalho explicita a estrutura conceptual da Política em Henrique Cláudio de Lima Vaz. Essa estrutura não fora explicitada nela mesma pelo próprio Lima Vaz, que, não obstante, de modo preciso, estabelecera suas linhas gerais no escrito "Ética e Direito", capítulo quarto dos Escritos de Filosofia II. Ética e Cultura, de 1988, mas escrito originalmente ainda em 1977, texto sobre o qual o trabalho se debruça, para efeito da explicitação da concepção vaziana da Política. O trabalho explicita inicialmente as linhas gerais do desenvolvimento dialético em Lima Vaz e sua concepção de que o método deve adaptar-se ao conteúdo. Em seguida, discute a ideia vaziana de sistema da filosofia e sua organização dialética; quando se passa então à tematização da estrutura silogística da Política, entendida como continuidade da Ética, no sentido de Aristóteles, e, portanto, como Ciência filosófica do Direito, no sentido de Hegel. Enfim, o trabalho busca mostrar a adequação de tal estrutura às estruturas da Ética e da Antropologia.

Palavras-chave: Aristóteles. Hegel. Antropologia. Ética. Filosofia política.

Abstract: This paper explains the conceptual framework of Politics in Henrique Claudio de Lima Vaz. This structure was not explicitly defined by Lima Vaz himself, although he precisely described its general lines in his writing "Ethics

\footnotetext{
* Este trabalho consiste numa versão reduzida de uma investigação mais aprofundada, a ser publicada proximamente, levada a termo junto à Faculdade Jesuíta - FAJE -, em Belo Horizonte, no ano letivo de 2018, período de gozo de duas licenças sabáticas concedidas ao autor pela Universidade Estadual do Centro-Oeste do Paraná - Unicentro/PR -, sem cujo apoio a realização desta pesquisa não teria sido possível.

* Professor do Departamento de Filosofia da Universidade Estadual do Centro-Oeste do Paraná (Unicentro). Artigo recebido em 17/02;2021 e aprovado para publicação em 22/02/2021.
} 
and Law", fourth chapter of Escritos de Filosofia II. Ética e Cultura, published in 1988, but originally written in 1977. The explication of Lima Vaz's conception of Politics undertaken here is based on the text above. First, the article will explain the general lines of Lima Vaz's dialectical development and his conception that a method must be adapted to the contents. Then, it discusses Lima Vaz's idea of a philosophical system and its dialectical organization. It proceeds by thematizing the syllogistic structure of Politics, understood as the continuity of Ethics in Aristotle's sense and, therefore, as the Philosophical Science of Law, as formulated by Hegel. Finally, the work seeks to show the adequacy of such a structure to the structures of Ethics and Anthropology.

Keywords: Aristotle. Hegel. Anthropology. Ethics. Political Philosophy.

\section{Considerações preliminares}

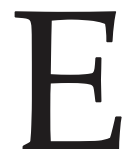
ste trabalho explicita a estrutura conceptual da Política ou a ideia do Direito em Henrique Cláudio de Lima Vaz. ${ }^{1}$ Os termos 'Política' e 'Direito' são usados aqui como sinônimos, isto é, no sentido próprio em que o filósofo ouro-pretano os utiliza; a saber, como designações distintas de uma e mesma ciência: de um lado, designada Política por Aristóteles e, de outro, chamada Filosofia do Direito por Hegel. Eis aí a constatação vaziana de uma identidade da Política de Aristóteles e da Filosofia do Direito de Hegel, uma constatação que tem por pano de fundo a pressuposição de uma estrutura comum entre a concepção de uma continuidade necessária entre a Ética e a Política no primeiro e a concepção dialética do Direito no segundo. Infelizmente, tal estrutura não foi explicitada nela mesma pelo próprio Lima Vaz, que, não obstante, de modo preciso, estabelecera suas linhas gerais.

A continuidade necessária da Ética e da Política é uma continuidade a um tempo lógica e ontológica, a qual se desenvolve mediante um movimento dialético, logo sistemático. De um lado, segundo o ponto de vista do ethos - simultaneamente individual e social -, a referida continuidade limitou-se a uma constatação empírica em Aristóteles, ${ }^{2}$ de outro, da perspectiva do discurso ou da organização das categorias éticas e políticas, foi sistematizada precisamente na Filosofia do Direito de Hegel. Este, contudo, não pensou tal continuidade a partir do ethos em seu desenvolvimento histórico concreto

\footnotetext{
${ }^{1}$ Henrique Cláudio de Lima Vaz nasceu em Ouro Preto, Minas Gerais, em 1921 e faleceu em Belo Horizonte, em 2002. Deixou extensa obra publicada e dezenas de materiais inéditos, muitos sobre Hegel e sua dialética, a qual sofrera uma transformação importante em Lima Vaz, para quem o método deveria adaptar-se ao conteúdo. Quando se impõe, para o filósofo, o problema da mediação entre a forma adequada do pensamento moderno - consubstanciado na dialética hegeliana - e o conteúdo principal, ético-metafísico, da tradição greco-cristã.

${ }^{2}$ Ver, ARISTOTE, L'Éthique a Nicomaque, X, 10, 1179 b 31-1181 b 23.
} 
ou da universalidade nomotética, propriamente greco-antiga, portanto, da physis como universalidade objetiva. Ao contrário, Hegel a tematizou no âmbito de sua contraposição à universalidade hipotética $a^{3}$ do Direito abstrato, moderno, e de sua suprassunção na circularidade dialética da substância ética, conformadora do Estado e da história mundial do espírito; quando, de certo modo, restaura a universalidade nomotética a partir da ideia do Estado. ${ }^{4}$ Mas falta a Hegel um desenvolvimento categorial que parta justamente do ethos, enquanto ainda situado no polo da natureza e o eleve ao polo de sua forma simbólica, a partir da universalidade nomotética ela mesma. Esse, ao que tudo indica, o intento de Lima Vaz.

Lima Vaz parece ter entrevisto essa lacuna já em seus primeiros textos acerca de questões éticas e políticas, ${ }^{5}$ entretanto, não chegou a escrever uma Política sistemática, isto é, uma Filosofia política ou uma Filosofia do Direito segundo o modelo dialético de sua Antropologia e de sua Ética filosóficas. Não obstante, o filósofo ouro-pretano deixara alguns escritos, anteriores à elaboração sistemática dessas disciplinas, em que a Política fundamental ou, o que para ele é o mesmo, a ideia do Direito é traçada em suas linhas gerais, assim como indicações acerca do lugar da Política ou do Direito no quadro teórico do que se poderia designar o sistema filosófico vaziano. Neste, a Política se funda na Etica e essa na Antropologia, que consiste em um desdobramento da Ontologia ou da Metafísica, a qual, a exemplo da Antropologia, se realiza na Ética ou como a Ética mesma, em sua unidade com a Política.

O texto capital na tematização vaziana de uma Política sistemática tem por título "Ética e Direito" e forma o capítulo quarto dos Escritos de Filosofia II. Ética e Cultura, de 1988, obra que recolhera diversos artigos antes publicados em revista e os refundira de modo a que se adequassem ao formato de livro. O referido capítulo fora publicado originalmente em 1977 - ano em que Lima Vaz iniciara seus cursos na UFMG sobre a Ciência da Lógica de Hegel -, sob o título "Antropologia e direitos humanos" 6 e como que, embora ainda sem a clareza da silogística desenvolvida nos

\footnotetext{
${ }^{3}$ Sobre a diferença e a discussão vaziana desses conceitos, ver H. C. DE LIMA VAZ, Ética e Direito, in Escritos de Filosofia II. Ética e Cultura, São Paulo: Loyola, 1988, p. 146-160; p. 163-172. Para sua discussão em Hegel, veja-se M. M. DA SILVA, Introdução ao problema da fundamentação especificamente filosófica do Direito contemporâneo. In Revista Guairacá, 21, (2005): 103-125, p. 110ss.

${ }^{4}$ Ver H. C. DE LIMA VAZ, Ética e Direito, in op. cit., p. 171-172.

${ }^{5}$ Ver, H. C. DE. LIMA VAZ, Moral, Sociedade e Nação, in Revista Brasileira de Filosofia, 53 (1964): 1-30; referido em H. C. DE LIMA VAZ, Ética e Direito, in op. cit., p. 141, nota 17. ${ }^{6}$ Ver, H. C. DE. LIMA VAZ, Antropologia e direitos humanos, in REB, 37 (1977): 13-40; referido em H. C. DE LIMA VAZ, Ética e Direito, in op. cit., p. 135, nota. Embora ao que parece, até aqui, descuidado pelos estudiosos de Lima Vaz, o artigo de 1977 se impõe como paradigmático no que diz respeito ao desenvolvimento dialético, isto é, sistemático, do pensamento do filósofo de Ouro Preto, sobretudo no concernente à sua filiação à forma de pensar preconizada por Hegel. Ver, H. C. DE. LIMA VAZ, Antropologia e direitos humanos, op. cit., p. 20; p. 39.
} 
anos seguintes, ${ }^{7}$ traça de modo preciso o percurso teórico que as futuras obras sistemáticas irão percorrer. Em vista disso, será precisamente esse o texto-base sobre o qual o presente trabalho irá debruçar-se, para efeito da explicitação da concepção vaziana da Política.

O trabalho explicita inicialmente as linhas gerais do desenvolvimento dialético em Lima Vaz e sua concepção de que o método deve se adaptar ao conteúdo. Em seguida, o trabalho discute a ideia vaziana de sistema da filosofia e sua organização dialética; quando passa à tematização da estrutura silogística da Política entendida como continuidade da Ética, no sentido de Aristóteles, e, portanto, como Ciência filosófica do Direito no sentido de Hegel. A título de conclusão, o trabalho mostra a adequação de tal estrutura com as estruturas da Ética e da Antropologia.

\title{
II. O sistema da filosofía em Lima Vaz e sua organização dialética
}

\begin{abstract}
O sistema, em Lima Vaz, é resultado de um desenvolvimento dialético que, como tal, se desdobra segundo silogismos diversos, cada um sob a forma de um momento do todo. Com isso, cada silogismo se mostra como a forma em que o conteúdo se dá a conhecer, constituindo uma disciplina
\end{abstract}

\footnotetext{
${ }^{7}$ Em 1977, quando publica o paradigmático "Antropologia e direitos humanos", provavelmente escrito em 1976, e pronuncia o curso - igualmente preparado no ano anterior - intitulado A teoria hegeliana do conceito, junto ao PPG em Filosofia da UFMG, Lima Vaz tematiza pela primeira vez os silogismos fundamentais da silogística hegeliana. Essa a ocasião em que o filósofo ouro-pretano comenta justamente o § 198 da Enciclopédia de 1830 - que discute o chamado silogismo do mecanismo, entendido como uma triplicidade de silogismos, em especial a Anotação a tal parágrafo, na qual Hegel estende o referido silogismo ao Estado - e o interpreta a partir da noção de Pessoa. Os silogismos aí tematizados irão conformar precisamente a silogística vaziana, que terá na refundição (termo de Lima Vaz) do artigo de 1977, ocorrida no capítulo Ética e Direito, dos Escritos de Filosofia II, em 1988, sua primeira formulação. Esta, em rigor, inicia sua gestação já mesmo em 1976, quando da preparação do curso acima referido e da menção, por Lima Vaz, ao silogismo U-P-S (que depois será o silogismo fundamental da Ética), o qual, na verdade, não é extraído da silogística hegeliana, mas consiste na formalização, pelo filósofo ouro-pretano, do capítulo primeiro (O conceito em geral) da Lógica subjetiva ou da Doutrina do conceito, da Ciência da Lógica. Ver, a respeito, H. C. DE LIMA VAZ, A teoria hegeliana do conceito. Curso ministrado junto ao Mestrado em Filosofia da UFMG, primeiro semestre de 1977, Caderno de anotações de H. C. de Lima Vaz. Memorial Pe. Vaz. Ficha 11, Armário 1, Gaveta 5. Fotocópia. Material disponibilizado ao autor em 2013, passim. É interessante observar que, embora trabalhe com a Lógica de Hegel desde pelo menos 1974, quando ministra um curso sobre a Enciclopédia, Lima Vaz introduz o silogismo U-P-S apenas em 1977, utilizando antes disso a estrutura S-P-U. Ver H. C. DE LIMA VAZ, A Enciclopédia de Hegel. Curso ministrado junto ao Mestrado em Filosofia da UFMG, 1974, Transcrição dos áudios dos cursos de H. C. de Lima Vaz. Memorial Pe. Vaz. Fita 64B. Cópia. Material disponibilizado ao autor em 2013, folha 1ss.
} 
determinada; esse o caso da Antropologia e o da Ética, as duas únicas disciplinas que Lima Vaz elaborou sistematicamente. No que diz respeito à Política, embora não haja para ela uma elaboração sistemática, Lima Vaz apresentara de modo pioneiro a sua estrutura silogística.

Em cada disciplina, portanto, o sistema implica admitir para o discurso em questão uma forma própria de sistematicidade. Segundo essa forma, no dizer de Lima Vaz, é possível expor a estrutura elementar dos momentos lógicos de tal discurso e a natureza do movimento dialético que o organiza como sistema. ${ }^{8}$ Porque se mostra sob a estrutura elementar dos momentos lógicos do discurso em questão e se move conforme a natureza do movimento dialético, bem como porque, assim, em cada caso, se apresenta sob uma ideia diretriz. ${ }^{9}$ a forma de sistematicidade aqui em jogo será sempre a forma silogística. Essa, contudo, não se mostra senão em sua conformação embrionária - em certo sentido, em suas linhas gerais, ainda aristotélica, embora se faça, em seu terceiro momento, necessariamente dialética ou, antes, hegeliana ${ }^{10}$-, quando da elaboração da Antropologia filosófica $^{11}$, na qual os momentos lógico-estruturais são entendidos como

${ }^{8}$ Ver H. C. DE LIMA VAZ, Escritos de Filosofia V. Introdução à Ética filosófica II, São Paulo: Loyola, 2000, p. 17. Ver, também, H. C. DE LIMA VAZ, Antropologia Filosófica I, São Paulo: Loyola, 1991, p. 160-161; p. 162-163ss.

${ }^{9}$ Ver H. C. DE LIMA VAZ, Escritos de Filosofia V, op. cit., p. 17; H. C. DE LIMA VAZ, Antropologia Filosófica I, op. cit., p. 10ss p. 157ss.

${ }^{10}$ Ver H. C. DE LIMA VAZ, Antropologia Filosófica I, op. cit., p. 161-163ss.

${ }_{11}$ Antes da primeira edição publicada de sua Antropologia filosófica, ocorrida em 1991-1992, Lima Vaz redigira duas versões preliminares, a título de texto básico para os cursos que ministrara, respectivamente na Faculdade de Filosofia e Ciências Humanas da Universidade Federal de Minas Gerais, de 1968 a 1972, e na Faculdade de Filosofia do Centro de Estudos Superiores S.J, de Belo Horizonte, em 1989 e 1990. Essas versões escolares, a partir das anotações de antigas alunas de Lima Vaz, as professoras Marilene R. de Mello Brunelli e Maria Eugênia Dias de Oliveira, foram "extremamente úteis" para a confecção da versão publicada; o que significa que muitos dos conteúdos desta estariam originalmente naquelas. Ver, $\mathrm{H}$. C. DE LIMA VAZ, Antropologia Filosófica I, op. cit., p. 7. Em todo caso, sabe-se que os textos que compõem os dois volumes da Antropologia Filosófica, tal como a obra fora publicada em 1991-1992, já estavam praticamente prontos sob a forma de manuscrito e serviram de base para o Curso de Antropologia Filosófica ministrado do ISI-CES nos dois semestres de 1985. Da mesma forma, no manuscrito referente ao Curso de Antropologia Filosófica do segundo semestre de 1968, ministrado na FAFICH/UFMG, para o que aqui interessa, o capítulo intitulado Introdução metodológica corresponde ao capítulo Objeto e Método da Antropologia Filosófica, da obra publicada em 1992. Ver, respectivamente, H. C. DE LIMA VAZ, Antropologia filosófica I. Curso ministrado junto à Graduação em Filosofia do ISI-CES, primeiro semestre de 1985, Manuscrito. Memorial Pe. Vaz. Ficha 40, ARM. Fotocópia. Material disponibilizado ao autor em 2018, passim. H. C. DE LIMA VAZ, Antropologia filosófica. Curso ministrado junto à Graduação em Filosofia da UFMG, segundo semestre de 1968, Transcrição de gravações e notas de aula de José Maria Moreira e Maria Eugenia. Memorial Pe. Vaz. Ficha 90, Armário 3, Gaveta 5. Fotocópia. Material disponibilizado ao autor em 2018, passim. Não obstante, considerando 1985 como a época da redação do texto definitivo da Antropologia e sua publicação efetiva em 1991-1992, bem como comparando-a com a Ética, publicada em 1999-2000, torna-se problemático (embora de modo apenas aparente) afirmar que a silogística vaziana mostra-se em sua conformação embrionária naquela e não já em sua especificidade própria 
polos epistemológicos fundamentais - opostos entre si - mediatizados por um termo médio ao nível do movimento dialético, que seria fundamentalmente um discurso sobre as categorias ${ }^{12}$. Essas conformadas ou mediadas nos limites do esquema (N) -> (S) -> (F), no qual (N) exprime a Natureza, (S) o Sujeito e (F) a Forma, as próprias categorias do discurso ou ainda o próprio $\mathrm{Eu}$, nos diversos planos de compreensão, mas sempre no âmbito da passagem da Natureza ou do dado à Forma, ao construído, passagem que tem precisamente no Sujeito, o termo médio do esquema, o elemento mediador dos extremos dialeticamente opostos. Em todo caso, já na Antropologia, Lima Vaz afirma que os polos são igualmente momentos ${ }^{13}$; assim, reconhece o caráter silogístico do esquema $(\mathrm{N}) \rightarrow(\mathrm{S})->(\mathrm{F})$, logo, toma-o como um silogismo fundamental que conforma, enfim, não só a Antropologia, mas também a Ética. ${ }^{14}$

Os silogismos fundamentais informadores da produção sistemática de Lima Vaz obedecem a uma transformação da dialética hegeliana, levada a termo pelo filósofo ouro-pretano, que corresponde justamente aos seus anos de ensino da Lógica especulativa na UFMG, a saber, de 1974 a 1986. ${ }^{15}$ Tais silogismos, pensados a partir de Hegel, são, em rigor: (1) P-S-U, Particular-Singular-Universal, que se deixa apreender e se apresenta como tal no esquema (N) -> (S) -> (F), na Antropologia filosófica, mas que conforma igualmente a Ética; na qual, não obstante, a partir daquele, emerge (2) o silogismo U-P-S, Universal-Particular-Singular, cujo ponto de partida é precisamente a razão prática, enquanto ideia diretriz e, portanto, universalmente objetiva, ${ }^{16}$ essa, em sua realização, implica (3) a abertura estrutural da categoria de pessoa mora ${ }^{17} \mathrm{e}$, com isso, a passagem ao silogismo P-U-S, Particular-Universal-Singular, como a estrutura fundamental que rege a Política. Assim, porquanto partem do indivíduo humano em sua existência particular concreta $(\mathrm{P})$, dada aí na natureza ou no mundo da vida, e em seu agir universal igualmente concreto (U), os dois primeiros silogismos se fundam no terceiro, que os conclui; precisamente aquele apresentado, de modo programático, ainda em 1977, no qual a particu-

mediante o esquema $(\mathrm{N})$-> $(\mathrm{S})$-> $(\mathrm{F})$, à diferença da estrutura PSU, explicitados a seguir. Essa, contudo, a conformação embrionária da silogística vaziana no esquema (N) -> (S) -> $(\mathrm{F})$, a tese que este trabalho segue; a qual, porém, devido ao escopo estrito do mesmo, será explicitada em outro momento.

12 Ver, H. C. DE LIMA VAZ, Antropologia Filosófica I, op. cit., p. 12-13; p. 166-167.

${ }^{13}$ Ver, H. C. DE LIMA VAZ, Antropologia Filosófica I, op. cit., p. 163-165.

${ }^{14}$ Neste caso, veja-se, H. C. DE LIMA VAZ, Escritos de Filosofia V, op. cit., p. 19ss.

${ }^{15}$ Lima Vaz lecionou na UFMG de 1965 a 1986. Entre 1974 e 1986, trabalhou especificamente com a Ciência da Lógica e a Enciclopédia, além da Fenomenologia do Espírito e a Filosofia do Direito, interpretadas a partir da Lógica, quando ofereceu cursos importantes no Mestrado em Filosofia. Esses cursos, assim como os materiais deles resultantes, estão no momento em processo de edição pelo autor do presente trabalho e outros estudiosos, devendo sair a lume nos próximos anos.

${ }^{16}$ Veja-se, H. C. DE LIMA VAZ, Escritos de Filosofia V, op. cit., p. 36.

${ }^{17}$ Veja-se, H. C. DE LIMA VAZ, Escritos de Filosofia V, op. cit., p. 36-37. 
laridade da Natureza ou do dado e a universalidade da Forma ou dos princípios sintetizam-se no Sujeito ou na Singularidade (S), em sua limitação eidética e em sua ilimitação tética. ${ }^{18}$ Lima Vaz parte, portanto, no primeiro silogismo, da particularidade do mundo objetivo ou da Natureza (P) e daí passa ao sujeito humano em sua singularidade (S), quando acede enfim à forma ou à universalidade objetiva, necessariamente, a universalidade constitutiva do próprio humano e da Lei e do Direito (U). Atingida essa universalidade, em rigor, nomotética, ${ }^{19}$ chega-se ao segundo silogismo, que tem ela própria como ponto de partida (U), para efeito de se pensar a existência propriamente ética, quando então se passa à particularidade $(\mathrm{P})$ e, enfim, à singularidade do sujeito ético $(\mathrm{S})$. Aqui, porém, ainda no bojo do desenvolvimento sistemático da Ética, portanto, nos limites do segundo silogismo, entra em ação igualmente a Política, que, por se desdobrar em continuação e contraposição àquela, exige para o indivíduo uma mediação adicional e, com isso, uma estrutura silogística mais fundamental.

Quer dizer, o silogismo P-U-S é pressuposto, no início (em P-S-U) e no final (em U-P-S), como a estrutura mediadora fundamental. Essa permite pensar o silogismo P-S-U como a estrutura conceptual da natureza ou do cosmo enquanto a Razão cósmica ela mesma, bem como o silogismo U-P-S enquanto a razão humana que se funda naquela, assumida como seu modelo essencial e, por isso, como Razão prática. Nessa medida, o silogismo P-U-S constituir-se-ia a um tempo enquanto estrutura lógica e ontológica ou dialética, conformando a unidade de Metafísica e Ética, tão insistentemente buscada por Lima Vaz em todo o seu percurso filosófico. Em vista disso, enfim, a estrutura conceptual da Política se mostraria como a realização mesma, a um tempo, da Metafísica e da Ética na vida concreta do cidadão.

Desse modo, o desenvolvimento dialético em jogo em P-U-S, que, para Lima Vaz, constitui a estrutura conceptual básica da ideia do político, ${ }^{20}$ assume um caráter a um tempo histórico e sistemático. Em vista disso, conforme o filósofo, assim como em S-P-U e em U-P-S, tal desenvolvimento tem que "acompanhar as formas históricas da dialética universal-singular na qual se exprime a relação do indivíduo à universalidade do Direito, com o fim de examinar a adequação dessas formas históricas às exigências teóricas dessa dialética" ${ }^{21}$ Pressupõe-se assim, movendo-se no espaço-tempo, uma dialética universal-singular; nesta, universal e singular constituem os polos

\footnotetext{
${ }^{18}$ Ver H. C. DE LIMA VAZ, Escritos de Filosofia V, op. cit., p. 20; H. C. DE LIMA VAZ, Antropologia Filosófica I, op. cit., p. 166-167.

19 Fazemos nossas as palavras de Lima Vaz: "Nomotética se diz propriamente da arte de legislar. Nomothétes é o legislador. Aqui aplicamos analogicamente o termo a uma ordem objetiva que se põe como lei e é, como tal, apreendida pela razão". Ver H. C. DE LIMA VAZ, Ética e Direito, in op. cit., p. 146.

${ }^{20}$ Ver, H. C. DE. LIMA VAZ, Ética e Direito, in op. cit., p. 141.

${ }^{21}$ Ver, H. C. DE. LIMA VAZ, Ética e Direito, in op. cit., p. 141, nota 20, à p. 142.
} 
de uma relação essencial: de um lado, a universalidade objetiva do logos ou a lei e o Direito; de outro, a particularidade do indivíduo, que ao ser negada naquela, nela o conserva como singularidade. ${ }^{22}$ Mas com isso se apresenta um importante problema metodológico.

Porque movendo-se realmente no espaço-tempo, tal dialética exige que seu desenvolvimento metódico acompanhe suas formas históricas ou, em outros termos, adapte-se a elas; essa a exigência segundo a qual o método se adapte ao conteúdo. ${ }^{23}$ Entretanto, isso exige antes, por sua vez, a crítica dessas formas no sentido de verificar a sua adequação às exigências teóricas daquela dialética, isto é, principalmente, à exigência de que as concepções de homem em jogo nas formas históricas várias da referida dialética logrem articulá-la corretamente; para o que se requer ainda a adequação de tais concepções às exigências conceptuais que se manifestam na analogia entre o ético e o político. ${ }^{24}$ No caso de Lima Vaz, a concepção que dá conta de todas essas exigências não é senão a do homem enquanto portador do $\log o s$ e, portanto, capaz de linguagem. ${ }^{25}$

Isso se mostra assim em razão de a dialética constituir-se histórica e sistematicamente, segundo seus diferentes modelos, de Platão a Hegel, como um caminho; esse definido por Platão como "o caminho através do logos", porquanto parte de ideias e permanece em ideias. ${ }^{26}$ Nessa medida, a dialética é essencialmente uma ontologia e avança a partir de oposições fundamentais, em especial a oposição finito-infinito (ou, no caso presente, a oposição singular-universal), que exprime a inteligibilidade discursiva do Ser; por isso, no dizer de Lima Vaz, "ela não serve de roteiro quando se pretende à análise, à classificação e à demonstração dos objetos finitos circunscritos nos limites de sua finitude" ${ }^{27}$ Conforme se aplique ao Ser, inclusive ao Ser humano, como na Antropologia, ou ao Agir, em particular ao agir humano, como na Ética, aquele método obedecerá a uma estrutura conceptual distinta.

Trata-se, na Antropologia, de uma Ontologia da pessoa humana e, na Ética, de uma Ontologia do agir humano. Por isso, nesta, em conformidade com o silogismo U-P-S, o ponto de partida são os princípios universais da Razão prática e seu ponto de chegada a assunção e a articulação de tais princípios na vida ética. Naquela, desenvolvida segundo o silogismo S-P-

\footnotetext{
${ }^{22}$ Ver, H. C. DE. LIMA VAZ, Ética e Direito, in op. cit., p. 143.

${ }^{23}$ Ver, H. C. DE. LIMA VAZ, Método e dialética, in E. F. DE BRITO; L. H. CHANG. Filosofia e método. São Paulo: Loyola, 2002, p. 9. Nesse locus, Lima Vaz afirma explicitamente que "o procedimento dialético é diferente segundo a diferença dos conteúdos que são pensados dialeticamente"; como exemplo do mesmo, ele cita precisamente as partes sistemáticas de sua Antropologia e sua Ética. Ver, H. C. DE. LIMA VAZ, Método e dialética, in op. cit., p. 15ss.

${ }^{24}$ Ver, H. C. DE. LIMA VAZ, Ética e Direito, in op. cit., p. 143.

${ }^{25}$ Ver, H. C. DE. LIMA VAZ, Ética e Direito, in op. cit., p. 142-144.

${ }^{26}$ Ver, H. C. DE. LIMA VAZ, Método e dialética, in op. cit., p. 12ss.

${ }^{27}$ Ver, H. C. DE. LIMA VAZ, Método e dialética, in op. cit., p. 15.
} 
-U, o ponto de partida é o dado, a Natureza ou o cosmos natural enquanto mundo da vida e seu ponto de chegada a Forma ou a pessoa humana, o Eu propriamente dito, a expressão de si mesmo do homem em mundo do sentido. A Política, por sua vez, à luz desses desenvolvimentos, e conforme o silogismo P-U-S, teria seu ponto de partida na particularidade do sujeito e seu ponto de chegada na singularidade deste como enunciador e portador de valores; em suma, como "capaz de articular-se com seus semelhantes na forma da vida política".$^{28}$ Assim, a universalidade objetiva, abstrata ou formal, dos princípios da Razão prática se faz a universalidade objetiva, agora concreta, da lei e do Direito vividos e compartilhados no âmbito da comunidade ética e, por conseguinte, da comunidade política.

A Política pressupõe a Ética e a Antropologia. A vida política não tem como ser vivida em sentido próprio sem que os princípios da Razão prática já tenham sido articulados pelo indivíduo no âmbito de sua existência própria ou em sua vida ética, tornando-se, na vida política, o termo médio de sua articulação com os seus semelhantes; assim como sem a plataforma do cosmo natural que, para esta, se impõe a partir do mundo da vida e da elevação do indivíduo humano de um ser de natureza a um ser de sentido. ${ }^{29}$ Em vista disso, pode-se dizer que os silogismos acima apresentados não conformam senão um único e mesmo silogismo em sua triplicidade constitutiva; portanto, constituem-se como um sistema triplamente ordenado ou, mais precisamente, intermediado.

\section{Para uma estrutura conceptual da Politica, sua fundação silogistica}

A Ética conforma-se sistematicamente segundo o silogismo U-P-S. Este designa o Universal objetivo como ponto de partida do conteúdo considerado ainda em sua abstração e que passa ao Particular, momento em que se cinde nele mesmo e entra assim no âmbito concreto da existência individual, quando enfim, se eleva ao Singular, ou à singularidade da vida propriamente ética. Lima Vaz é explícito quanto à origem de tal silogismo; ao final da Introdução à Ética filosófica 2, ele se refere ao mesmo como sendo a estrutura dialética interna do conceito (em cada caso, da ideia diretriz em questão) e, desse modo, indica os parágrafos 31 e 32 das Linhas fundamentais da Filosofia do Direito de Hegel como sua fonte e

\footnotetext{
${ }^{28}$ Ver, H. C. DE. LIMA VAZ, Ética e Direito, in op. cit., p. 143.

${ }^{29}$ Sobre as noções de 'cosmo natural' e de 'mundo da vida', tal como utilizados nesta passagem, veja-se, H. C. DE LIMA VAZ, Cristianismo e consciência histórica I. In H. C. DE LIMA VAZ, Escritos de Filosofia VI. Ontologia e história. São Paulo: Loyola, 2001, p. 165ss. Essa obra, em seu conjunto, foi publicada em 1968, a partir da recolha de artigos publicados originalmente em revistas diversas, na década de 1950.
} 
sua referência fundamental. ${ }^{30}$ Nesses parágrafos, entretanto, Hegel apenas alude à estrutura geral do automovimento do conceito, sem se ater a seus modos, e, em termos mais estritos, à dependência metodológica da Filosofia do Direito em relação à Ciência da Lógica.

De acordo com Hegel, no $\S 31$ das Linhas fundamentais da Filosofia do Direito, "o método segundo o qual, na ciência, o conceito se desenvolve a partir de si mesmo e não é senão um ato imanente de progredir e de produzir suas determinações [...] é aqui igualmente pressuposto a partir da Lógica" ${ }^{31} \mathrm{E}$ ainda, no $\S 32$ da mesma obra:

As determinações no desenvolvimento do conceito são, de um lado, elas mesmas conceitos; de outro, porque o conceito é essencialmente como ideia, elas são na forma do ser-aí, e a série dos conceitos que daí resulta é, por isso, ao mesmo tempo, uma série de configurações. ${ }^{32}$

Por esses parágrafos, infelizmente, é impossível entender a referência de Lima Vaz. O acordo com a discussão do filósofo ouro-pretano limita-se à afirmação de que a determinações ou os modos de ser-aí do conceito, e que resultam, pois, de seu desenvolvimento interno, são eles mesmos conceitos. Hegel não escreve em nenhum momento (destes parágrafos) que o movimento de determinação vai do Universal ao Particular e ao Singular; não obstante, quando afirma que "cada grau de desenvolvimento da ideia da liberdade tem seu direito característico porque ele é o ser-aí da liberdade numa de suas determinações próprias", ${ }^{33}$ ou que "a progressão não se produz por meio da garantia de que há diferentes relações e, em seguida, pela aplicação do universal a tal material tomado de outra parte", ${ }^{34}$ é possível perceber - nesses lugares - as linhas de forças que informam o princípio metodológico de Lima Vaz de que o método tem que se adaptar ao conteúdo. Não obstante, Hegel afirma que o método da Filosofia do Direito é pressuposto a partir da Lógica; nesta obra, em sua terceira parte, na Lógica do Conceito, o ponto de partida de Hegel é a tematização do conceito de conceito, então assumido como o Universal que se particulariza e, então, se autodetermina em sua liberdade para si, fazendo-se portanto singular concreto. Essa, entretanto, é apenas a estrutura geral do movimento interior do Conceito, o silogismo U-P-S que daí se extrai é a forma invertida de S-P-U, o silogismo do Dasein, isto é, do ser-aí, que justamente por isso parte do ser-aí tomado como dado, enquanto o conceito imediato ou em geral ${ }^{35}$; da mesma forma, à diferença do silogismo

\footnotetext{
${ }^{30}$ Ver, H. C. DE LIMA VAZ, Escritos de Filosofia V, op. cit., p. 22. Ver também, H. C. DE LIMA VAZ, Escritos de Filosofia IV. Introdução à Ética filosófica 1. São Paulo: Loyola, 1999, p. 75.

${ }^{31}$ G. W. F. HEGEL, GPhR, Werke 7, § 31, p. 84.

${ }^{32}$ G. W. F. HEGEL, GPhR, op. cit., § 32, p. 85.

${ }^{33}$ G. W. F. HEGEL, GPhR, op. cit., § 30, Anotação, p. 83

${ }^{34}$ G. W. F. HEGEL, GPhR, op. cit., § 31, p. 84.

${ }^{35}$ Hegel não utiliza especificamente em nenhum lugar a forma U-P-S como expressão de um silogismo determinado, no caso como a inversão de S-P-U. No entanto, ao descrever o
} 
vaziano, essa estrutura não é fixa em nenhuma ciência. U-P-S, porém, não é o silogismo do Dasein, mas antes o da Razão prática, ou o dos princípios práticos e de sua realização.

Enquanto forma invertida de S-P-U, e, portanto, posterior a ela, U-P-S é inicialmente a primeira figura do silogismo de reflexão. Isso justifica o uso que dele faz o filósofo de Ouro Preto, quando o coloca como o segundo momento de seu sistema e, assim, pressupõe de um lado P-S-U (como primeira premissa de um tríplice silogismo) e, de outro, P-U-S (como conclusão); caso em que estes seriam respectivamente silogismo do Dasein e silogismo da Necessidade. No entanto, ao tematizá-lo no quadro teórico do silogismo do método, Lima Vaz parece assumi-lo de saída como silogismo da necessidade, que, conforme Hegel, ao contrário do silogismo da reflexão, não pressupõe uma conclusão para suas premissas; mas antes, seus termos permanecem, conforme seu conteúdo substancial, em relação idêntica, como em si e para si, um com o outro; havendo uma essência que os perpassa, na qual as determinações de singularidade, particularidade e generalidade são apenas momentos formais. ${ }^{36}$ Não obstante, P-S-U se mostra em Hegel como a segunda figura dos três silogismos, sendo S-P-U a primeira e P-U-S (como inversão de S-U-P) a terceira figura, ${ }^{37}$ tem-se assim, de um lado, um silogismo do Ser-aí - de segunda figura - em Lima Vaz que é o ponto de partida imediato de seu filosofar e, portanto, comum ao procedimento adotado na Antropologia e na Ética; de outro, comparecem um silogismo de reflexão, de primeira figura,

processo de particularização e de singularização do conceito universal ele aceita e mesmo assume tal inversão como possível e como adequada. Ver, G. W. F. HEGEL, Wissenschaft der Logik, II, Werke 6, p. 273-274.

${ }^{36}$ Ver G. W. F. HEGEL, Wissenschaft der Logik, II, op. cit., p. 393. Aqui não há necessariamente um problema quanto à figura do silogismo e sim no concernente à sua função. Ao afirmar que U-P-S (ou S-P-U) é um silogismo da necessidade, por exemplo no Curso de Introdução à Ciência da Lógica do segundo semestre de 1985, A ideia absoluta, Lima Vaz o toma no quadro teórico do terceiro silogismo da ideia da filosofia. Este, porém, não pode ser o caso da Etica, a qual exige a realização mesma do universal, por conseguinte, no âmbito da Política; o que ocorre nos limites do chamado silogismo do conceito, que Hegel não tematiza, mas que se exprime na categoria da objetividade e, assim, se presta melhor ao esquema U-P-S tal como Lima Vaz o concebe. Situação em que, no entanto, embora não se apresente como silogismo da reflexão teórica, ele o será necessariamente da reflexão prática. Ver, G. W. F. HEGEL, Wissenschaft der Logik, II, op. cit., p. 402; H. C. DE LIMA VAZ, A teoria hegeliana do conceito, op. cit., passim.

${ }^{37}$ Quanto à forma SUP e à sua invertida PUS, Hegel utiliza a primeira na Grande Lógica e a segunda na Lógica da Enciclopédia. Levando em conta esse e outros usos, numa reconstrução ideal da Silogística hegeliana, realizada em Hegel e a Ideia de um Idealismo especulativo da Subjetividade e da Intersubjetividade, op. cit., p. 263ss, o autor do presente trabalho localizou as formas invertidas no âmbito do silogismo de reflexão, sendo a segunda figura (que Lima Vaz não utiliza em sua forma invertida) também presente no silogismo da necessidade, e não no do ser-ai. Situação que permite ao filósofo usar igualmente as duas formas invertidas como adequadas ao seu propósito e como lastreadas pelo texto de Hegel. Ver G. W. F. HEGEL, Wissenschaft der Logik, II, op. cit., p. 355; p. 367; p. 369; G. W. F. HEGEL, Enzyklopädie, I. Die Wissenschaft der Logik, Werke 8, § 186, p. 338; § 187, p. 338; § 198, p. 355-356. 
e outro de necessidade, de terceira figura; o que se mostra significativo para a economia do sistema vaziano. Lima Vaz entende o desenvolvimento dialético como um discurso sobre as categorias; disso resulta que seu ponto de partida seja o Particular ao nível do silogismo do Dasein e o Universal objetivo ao nível da reflexão; já seu ponto de chegada é a cisão (ou abertura) de U-P-S a P-U-S, que na verdade é o pressuposto da segunda premissa de U-P-S (PS), que, tal como a primeira premissa de P-S-U (PS), tem U como mediador, repetindo-se portanto nos dois primeiros silogismos, mostrando-se como fundamento de ambos e revelando a insuficiência de U-P-S enquanto mediação da segunda premissa de P-S-U (SU), que teria de ser mediada por P de S-P-U, mas o é de fato por P de U-P-S, como inversão daquele. O mesmo ocorre, por conseguinte, com a primeira premissa de U-P-S, a ser mediada por U-S-P e não por P-S-U. Vejamos isso no gráfico abaixo:

\begin{tabular}{|c|c|c|c|c|c|c|c|c|}
\hline \multirow{2}{*}{ Silogismos } & \multicolumn{4}{|c|}{ Processo ideal } & \multicolumn{4}{c|}{ Processo real } \\
\cline { 2 - 9 } & Premissa1 & Premissa2 & Conclusão & Resultado & Premissa1 & Premissa2 & Conclusão & Resultado \\
\hline P-S-U & PuS & SpU & PsU & U-P-S & PuS & UpS & PsU & U-P-S \\
U-P-S & UsP & PuS & UpS & S-U-P & PsU & PuS & UpS & S-U-P \\
P-U-S & PsU & UpS & PuS & S-P-U & PsU & UpS & PuS & S-P-U \\
\hline
\end{tabular}

No quadro acima, os três silogismos fundamentais assumidos por Lima Vaz são apresentados a partir do modo como eles se mostram em Hegel, mas nos limites em que eles se põem em relação no próprio Lima Vaz. No processo ideal, assim como no real, o silogismo que se impõe como fundamento essencial ou mediador universal é justamente P-U-S, pressuposto como início em P-S-U e posto como fim em U-P-S, logo revelando-se como determinante ao fim ou na conclusão do processo silogístico total. Não obstante, devido a U-P-S e o próprio P-U-S serem formas invertidas, respectivamente de S-P-U e de S-U-P, e por se mostrarem com isso como silogismos de reflexão, eles terminam por contradizer o processo real, em especial pela inserção de P-S-U como mediador na primeira premissa de U-P-S, em lugar de U-S-P, e de U-P-S na segunda premissa de P-U-S, em lugar de S-P-U. U-S-P e S-P-U, respectivamente o pressuposto e o posto por P-U-S, o mediador do silogismo total, cujo resultado final é S-P-U, o silogismo do Dasein em sua primeira figura, posto por P-S-U no processo ideal.

Quanto ao que se afirmou acima, é interessante observar que Lima Vaz ele mesmo indica as relações fundamentais entre P-U-S e U-P-S quando, ao falar do processo de universalização do homem como animal político em Aristóteles, o entende segundo a estrutura mesma do silogismo U-P-S, então referenciado mediante a indicação dos §§ 5-7 das Linhas funda- 
mentais da Filosofia do Direito de Hegel. ${ }^{38}$ Neste caso, Lima Vaz se mostra mais explícito que na indicação mais acima referida e sugere que se leia os parágrafos em questão juntamente com as respectivas notas; da mesma forma, algumas páginas mais adiante, o filósofo ouro-pretano afirma:

No silogismo dialético, como é sabido, as determinações do conceito universal, particular, singular - ocupam respectivamente os extremos e o meio-termo, interpenetrando-se num círculo que constitui propriamente o movimento dialético ou a racionalidade (das Vernünftige) do real. ${ }^{39}$

$\mathrm{Na}$ indicação das referências que justificam o trecho acima, Lima Vaz elenca o § 181 e a Anotação ao $§ 198$ da Ciência da Lógica da Enciclopédia, assim como a seção 1,3 do segundo tomo da Grande Lógica. Nessas referências, tal como nos §§ 5-7 da Filosofia do Direito, está em jogo para Hegel a estrutura geral do silogismo e não os silogismos tomados cada um por si. Não obstante, quando trata do mecanismo absoluto no $\S 198$ da Lógica da Enciclopédia, Hegel diz que S-P-U é uma triplicidade de silogismos e dá informações adicionais sobre U-S-P e P-U-S, ocasião em que, precisamente na Anotação à qual Lima Vaz nos remete em duas de suas notas, ${ }^{40}$ o filósofo alemão afirma que, como o sistema solar, no domínio prático, o Estado é um sistema de três silogismos. Lima Vaz parece ter levado essa afirmação muito a sério; no entanto, prefere usar a forma U-P-S ao invés de S-P-U e P-S-U ao invés de U-S-P, mantendo intacta apenas P-U-S.

Ao que tudo indica, Lima Vaz é consequente com a inversão hegeliana de S-U-P em P-U-S na Enciclopédia. Em vista disso, o filósofo ouro-pretano mantém igualmente a inversão de S-P-U, usando, pois, respectivamente, P-S-U (sem inversão) e U-P-S como os silogismos fundamentais da Antropologia e da Ética, bem como P-U-S, o silogismo da Política. Explicitar esse último à luz da referência de Lima Vaz a Hegel, e o acordo de fundo entre os dois filósofos, eis o objeto da próxima seção.

\section{O sistema da Politica e seu desenvolvimento dialético}

À diferença da Ética, mas seguindo de certo modo a dialética que a constitui, a Política assume para si o silogismo P-U-S, cujo ponto de partida é já a existência individual e concreta, mas a da Polis ou a do grupo social, isto é, a comunidade política à qual o indivíduo pertence. Como visto mais acima, este silogismo da Política tem P-S-U como sua primeira premissa e U-P-S como sua segunda premissa, convertendo-se assim ele mesmo,

\footnotetext{
${ }^{38}$ Ver H. C. DE LIMA VAZ, Ética e Direito, in op. cit., p. 143, nota 21.

${ }^{39}$ Ver H. C. DE LIMA VAZ, Ética e Direito, in op. cit., p. 145, nota 30.

${ }^{40}$ Ver H. C. DE LIMA VAZ, Ética e Direito, in op. cit., p. 145, notas 29 e 30.
} 
enquanto sua conclusão, no movimento imanente daquelas premissas, no conteúdo que as perpassa e na forma em que elas se concluem. Entretanto, se esta forma indica bem a origem da silogística vaziana, aquele conteúdo, na medida em que é reivindicado como histórico e concreto, exige uma explicitação adicional.

Temos aqui a retomada da tese aristotélica da Política entendida como uma continuidade da Ética e, portanto, apresentada como uma ciência prática e não teórica. Não obstante, a tese aristotélica é apresentada conforme a estrutura sistemática de um silogismo dialético-especulativo, típico da dialética hegeliana ou, pelo menos, nela inspirado. Leiamos Lima Vaz:

[...]. Há, pois, como viu Aristóteles, uma continuidade necessária entre a ética e a política: a dialética particular-universal-singular desdobra-se no campo da existência individual como circularidade dialética do ético e no campo da existência social como circularidade dialética do político. Mas é preciso convir que nem todas as concepções do homem logram articular corretamente essa dialética e é permitido supor que a inadequação de algumas dessas concepções às exigências conceptuais que se manifestam na analogia entre o ético e o político seja um dos problemas fundamentais do pensamento político contemporâneo. Assim, um dos caminhos para se estudar a relação entre o ético e o político ou entre a Ética e o Direito, e que aqui pretendemos seguir, oferece-se no terreno da evolução histórica do motivo antropológico que subjaz à dialética do particular-universal-singular que constitui a estrutura conceptual básica da ideia do político. ${ }^{41}$

Ora, com isso Lima Vaz pretende afirmar que a Política se constitui como a continuidade necessária da Ética em razão de que ambas possuem a mesma estrutura dialética de fundo, ainda que diferenciada em seu desenvolvimento concreto. Assim, porque se desdobra no campo da existência individual como circularidade dialética do ético, tal estrutura consiste tanto no ponto de partida da Antropologia, que estabelece a categoria de pessoa - aqui enquanto pessoa propriamente humana - quanto no ponto de chegada da Ética, que por sua vez estabelece a de pessoa moral. Da mesma forma, porque se desdobra no campo da existência social como circularidade dialética do político, a referida estrutura consiste no termo médio adequado ou o solo em que a Antropologia e a Ética se desenvolvem, em suma, o solo em que a pessoa ela mesma se reconhece a si mesma e aos outros como membros de uma e mesma comunidade ou, em outros termos, a si mesma como animal político ou capaz de linguagem. ${ }^{42}$ Neste sentido, a tarefa da Política é precisamente a instauração do logos universal no qual o indivíduo empírico se eleva e no qual sua particularidade se conserva como singularidade. ${ }^{43}$

\footnotetext{
${ }^{41}$ Ver H. C. DE LIMA VAZ, Ética e Direito, in op. cit., p. 141.

${ }^{42}$ Ver H. C. DE LIMA VAZ, Ética e Direito, in op. cit., p. 143.

${ }^{43}$ Ver H. C. DE LIMA VAZ, Ética e Direito, in op. cit., p. 142ss.
} 
O logos universal é assim, na Política ou conforme o silogismo P-U-S, igualmente o mediador universal, pressuposto na Ética a título de universalidade objetiva dos princípios da Razão prática e, portanto, como o fundamento do agir ético e da vida ética; portanto, segundo o silogismo U-P-S. Desse modo, enquanto assumidos e vividos pelo indivíduo humano na particularidade de seu existir concreto, tais princípios se particularizam e se tornam plurais segundo formas históricas as mais diversas, as quais não só interpelam o indivíduo, mas também, a um tempo, incidem diretamente na concepção de homem que o informa, possibilitando ou impossibilitando a articulação do ético e do político em cada caso concreto, individual, social ou epocal. Em suma, à luz do silogismo fundante da Antropologia, S-P-U, tudo se resume à capacidade do indivíduo em elevar-se àquela universalidade, o que implica sua capacidade em conceber-se e assumir-se como portador e enunciador do logos.

Eis aí o momento em que a estrutura tríplice do silogismo político (ou os três silogismos do Estado tematizados por Hegel e apropriados por Lima $V_{a z}{ }^{44}$ intercede. Leiamos, portanto, em Hegel, a descrição desse silogismo constitutivo da dialética da ideia do político, ou, mais precisamente, do Estado:

Como o sistema solar, assim, por exemplo, no domínio prático, o Estado é um sistema de três silogismos: 1. [em S-P-U] O Singular (a pessoa) conclui-se, por meio de sua Particularidade (as necessidades físicas e espirituais, o que, mais desenvolvido para si, dá a sociedade civil), junto com o Universal (a sociedade [política], o direito, a lei, o governo). 2. [em U-S-P] A vontade, atividade dos indivíduos [S], é o mediatizante, que dá satisfação, implementação e efetivação $[\mathrm{P}]$ às carências $[\mathrm{U}]$ tanto do indivíduo na sociedade, no Direito etc., como da sociedade, do Direito e assim por diante. 3. Mas [em P-U-S] o Universal (Estado, Governo, Direito) é o termo médio (Mitte) substancial no qual os indivíduos e sua satisfação têm e mantêm sua realidade (Realität), mediação e subsistência [P] implementadas [S]. Cada uma das determinações, enquanto a mediação a conclui-junto com o outro extremo, precisamente aí se conclui-junto consigo mesma. É só por meio da natureza desse concluir-junto, por meio dessa tríade de silogismos com os mesmos termini, que um todo é verdadeiramente entendido em sua organização. ${ }^{45}$

Os três silogismos de que fala Hegel são, respectivamente, S-P-U, U-S-P e P-U-S, tal como apresentados no caput do parágrafo em questão; em seu conjunto, eles conformam um movimento de realização cujo ponto de partida é o ser-aí, cuja mediação é a reflexão e cujo ponto de chegada é a necessidade. Todos, na verdade, constituídos pelos mesmos termos e conformados em momentos distintos de um único e mesmo silogismo, o primeiro, que tem nele, como seus mediatizantes e seus mediatizados, os outros dois. Neste caso, à diferença de Lima Vaz, Hegel parte do Ser-aí, do Singular (S) ou da pessoa humana em sua imediatidade e não da Reflexão, de seu ser-situado ou de sua Particularidade $(\mathrm{P})$ - as necessidades físicas

${ }^{44}$ Ver H. C. DE LIMA VAZ, Ética e Direito, in op. cit., p. 145, notas 29 e 30.

${ }^{45}$ G. W. F. HEGEL, Enzyklopädie, I, op. cit., § 198, Anotação, p. 356. 
ou espirituais e a própria sociedade civil -, que é o elemento mediador no primeiro silogismo e, por isso, o termo médio pelo qual o Singular se conclui-junto com o Universal (U), a sociedade política, o Direito, a Lei, o Governo. No filósofo ouro-pretano, o ponto de partida no primeiro silogismo (P-S-U) é o próprio ser-situado (P), ou a Natureza, o cosmo natural ou o mundo da vida como plataforma do ser-situado da pessoa (S); esta consiste na mediação por que seu ser-situado (sua natureza, o mundo da vida e as circunstâncias contingentes de seu existir) se conclui-junto com as formas simbólicas às quais o indivíduo se eleva, nas quais este se descobre pessoa, logo pertencente a uma universalidade objetiva, nomotética, identificada com a Razão cósmica (U), assumida como modelo de seu ser e de seu agir. No segundo silogismo (U-S-P), em Hegel, as carências - a um tempo do indivíduo, da sociedade, bem como do Direito - são o Universal (U), que, só por meio da atividade dos indivíduos, isto é, mediante sua vontade (S), pode ser satisfeita, implementado ou efetivado; tem-se aqui, porém, uma universalidade meramente hipotética, subjetiva, que pode se realizar ou não e, com isso, completamente distinta daquela em U-P-S, fundante da Ética vaziana. Universal (U) é aqui o âmbito dos princípios da Razão prática, as leis e os valores que a constituem; tais princípios, leis e valores são diversamente pressupostos pelos indivíduos situados e nestes se particularizam $(\mathrm{P})$ na medida em que estes se sabem portadores do logos universal, que então neles se manifesta porquanto é enunciado constituindo pois a vida ou a comunidade propriamente ética (S). Para isso, contudo, assim como em Hegel, há que intervir P-U-S; silogismo cujo procedimento dialético parece ser o mesmo em Hegel e em Lima Vaz.

Em Hegel, os indivíduos e suas carências constituem o ponto de partida, portanto a Particularidade (P) a ser mediada, ou elevada ao Universal (U), para que a satisfação dos indivíduos então se realize (S). O Universal, logo o Estado, o Governo, o Direito, como "o termo médio substancial no qual os indivíduos e sua satisfação têm e mantêm sua realidade (Realität), mediação e subsistência implementadas" ${ }^{46}$ consiste na universalidade objetiva, logo nomotética, que é a da ideia absoluta sendo em si, para nós, ou, o que é a mesma coisa, o espírito objetivo, ${ }^{47}$ esse, o ser-aí ou a efetividade da ideia cujo saber especulativo é a efetividade mesma dos homens (o saber do saber destes de que sua essência, meta e objeto é a liberdade), "não a ideia que eles têm, mas a ideia que eles $s \tilde{a} 0^{\prime \prime}{ }^{48}$ Neste caso, a satisfação das carências (Bedürfnisse) dos indivíduos não é a mera satisfação de bens exteriores, mas a da própria liberdade, que, como tal, só é possível em um Estado ético; por isso, Hegel pode afirmar que cada determinação, enquanto a mediação a conclui-junto com o outro extremo, se conclui-junto consigo mesma, sendo só por meio da natureza desse concluir-junto que um todo

\footnotetext{
${ }^{46}$ G. W. F. HEGEL, Enzyklopädie, I, op. cit., § 198, Anotação, p. 356.

${ }^{47}$ G. W. F. HEGEL, Enzyklopädie, III. Die Philosophie des Geistes, Werke 10, § 483, p. 303.

${ }^{48}$ G. W. F. HEGEL, Enzyklopädie, III, op. cit., § 482, Anotação, p. 302.
} 
é verdadeiramente entendido em sua organização. Tem-se aqui, portanto, não só a ideia do Estado ou a de uma Filosofia do Direito, mas também uma ideia do homem, logo de uma Antropologia, e uma ideia do agir humano, enfim, de uma Etica cuja realização se impõe à ideia mesma do Estado como uma necessidade.

Ainda em relação ao silogismo P-U-S, agora conforme a posição de Lima Vaz, o ponto de partida é a particularidade do indivíduo concreto, em seu caráter empírico e em sua situação natural (P). Essa particularidade constitui o polo do indivíduo ou antes do homem individual enquanto portador do $\log o s$ e, portanto, se mostra como a particularidade subjetiva deste. Porque o logos é justamente a condição essencial da expressividade do ser humano, isso significa que ele se faz necessariamente o outro polo fundamental da dialética constitutiva da existência política, o qual, enquanto universalidade objetiva (U), conforme Lima Vaz, "se exprime, por sua vez, numa dialética formal de valores e numa lógica do dever-ser: o bem e o mal, o justo e o injusto etc." ${ }^{\prime 9}$ Em vista disso, o ponto de chegada é a singularidade do indivíduo assim elevado à universalidade; logo, feito de si mesmo e por si mesmo um universal concreto capaz de articular a universalidade objetiva do $\log o s$ e a universalidade subjetiva e concreta que o logos assume no próprio indivíduo em sua condição de animal político ou capaz de linguagem, portanto, no espaço livre da existência política (S).$^{50} \mathrm{O}$ indivíduo se faz assim não só pessoa moral e cidadão de um Estado, mas o Estado mesmo; porquanto neste se dá suas leis e nestas se reconhece a si próprio, visto que elas resultam de um empreendimento livre e intersubjetivo, cujo logos, desde o início, se mostrou universal. Em suma, um universal a um tempo abstrato e objetivo - porque os valores éticos, a lei e o Direito - e subjetivo e concreto, porque assumido no indivíduo que, por isso, atualiza sua condição de animal político ou capaz de linguagem.

Enfim, é preciso reconhecer o papel da natureza em Hegel, lembrado - na citação acima - quando este inicia sua apresentação dos três silogismos comparando o Estado com o sistema solar. Algo que, embora não discutido aqui - devido ao escopo deste trabalho - é consistente com a tese segundo a qual "praticamente porta-se o homem ante a natureza, como algo imediato e exterior a ele próprio, como um indivíduo imediatamente exterior e, assim, sensível, que, porém, também com direito, se toma como fim para os objetos da natureza".$^{51}$ Hegel reconhece da parte do homem, nesse trecho e mais adiante, uma conduta prática (praktisches Verhalten) em relação à natureza, que, de um modo ou de outro, guarda ainda um papel constitutivo na determinação do desejo-à-busca-de-si (Begierde, welche selbstsüchtig) naquele, ${ }^{52}$ isso concorda em linhas gerais como a concepção

${ }^{49}$ Ver H. C. DE LIMA VAZ, Ética e Direito, in op. cit., p. 143.

${ }^{50}$ Ver H. C. DE LIMA VAZ, Ética e Direito, in op. cit., p. 143-144.

${ }^{51}$ G. W. F. HEGEL, Enzyklopädie, II. Die Naturphilosophie, Werke 9, § 245, p. 13.

${ }^{52}$ G. W. F. HEGEL, Enzyklopädie, II, op. cit., § 245, Adendo, p. 14. 
grega de natureza e com a concepção pressuposta por Lima Vaz em sua Antropologia. Caso em que a leitura vaziana do esquema $(\mathrm{N})->(\mathrm{S})->(\mathrm{F})$ entendido, em rigor, como silogismo, bem como a interpretação deste, no presente trabalho, como o silogismo P-S-U se mostram igualmente corretas.

Isso implica reconhecer, em Hegel e em Lima Vaz, a existência de uma Razão cósmica, a título de universalidade objetiva, plasmadora de um mundo da vida, no qual o ser humano pode viver e se realizar, a um tempo, como ser de natureza e como ser de razão. Implica reconhecer, igualmente, em ambos os autores, o Estado como a plenitude dessa universalidade no tempo e na história, segundo a contingência de cada época e conforme a capacidade do indivíduo humano em assumir-se como portador e enunciador do logos universal ou como um momento finito, mas essencial, da efetivação do conceito especulativo ou da ideia que se sabe a si mesma como livre, enquanto determinação do próprio espirito infinito. Nessa medida, a Política, em sua estrutura conceptual, se faz necessariamente Ontologia; a qual, a exemplo da Ética, se apresenta como uma Ontologia do agir humano, mas uma Ontologia do agir político.

\section{Considerações finais}

A Política, em Lima Vaz, consiste no desenvolvimento dialético da Ética para além do campo da existência individual como circularidade do ético; com isso, adentra o campo da existência social como circularidade do político. Tal como a Ética, a Política é uma Ontologia do agir humano; mas, à diferença da primeira - que é uma Ontologia do agir individual e, portanto, ético -, a segunda consiste numa Ontologia do agir social ou político. Situação em que, embora se desenvolvam mediante procedimentos distintos, ambas têm em comum certa interdependência.

A interdependência da Ética e da Política é verificável já a partir de suas respectivas estruturas silogísticas, de seu entrelaçamento e sua interpenetração. Se o desenvolvimento dialético do silogismo ético (U-P-S) pressupõe P-S-U e P-U-S, respectivamente, como mediação de UP e de PS (conforme o processo UsPuS), o desenvolvimento dialético do silogismo político (P-U-S) pressupõe P-S-U e U-P-S, para a respectiva mediação de PU e de US (de acordo com o processo PsUpS). É interessante observar que a efetivação do ético e a do político se pressupõem mutuamente (PuS em UsPuS e UpS em PsUpS), o que denota a impossibilidade de se separar Ética e Política e, portanto, na ocorrência de tal separação, a crise sem fim e a dissolução de ambas. Outro aspecto importante é a pressuposição do elemento antropológico pela Ética e pela Política (fato indicado por UsP em UsPuS e por PsU em PsUpS); isso significa que a Antropologia, como Ontologia do Ser humano, é o fundamento comum de ambas. Mas, e a Antropologia? 
O desenvolvimento dialético do silogismo antropológico (P-S-U) ocorre mediante o processo PuSpU, que pressupõe a universalidade objetiva tal como realizada na Política e que a põe segundo sua pressuposição pela Ética, isto é, a título de fundamento desta ou como a ideia mesma da Razão prática. Disso se depreende que a Antropologia funda a Ética, mas não a Política, sendo, ao invés, fundada por esta; consequência inevitável da circularidade dialética do ético e do político enquanto plasmação de um mundo propriamente humano - habitável pelo ser humano -, pensada a partir do exame crítico das formas históricas da dialética universal-singular. Essas devem adequar-se a certa concepção do ser humano, da qual, por sua vez, se exige articular de modo igualmente adequado aquela dialética; caso em que tal concepção e tal articulação não podem ser estabelecidas senão de modo onto-político. Quer dizer, segundo a capacidade do ser humano, em cada época determinada, de assumir seu papel de portador e enunciador do logos em relação a si mesmo e, em sua articulação com seus semelhantes, estabelecer uma ideia adequada de si mesmos.

Se há um motivo antropológico subjacente à dialética do particular-universal-singular, que constitui a estrutura básica da ideia do político, e se tal motivo evolui historicamente a ponto de oferecer um caminho para o estudo da relação do ético e do político, o referido motivo não pode se estabelecer senão politicamente. Isso porque, se a Ontologia do agir social ou político, isto é, a Política mesma, consiste em um desdobramento da Ética enquanto Ontologia do agir individual ou ético, assim como esta, aquela será igualmente uma ciência prática e seu desenvolvimento dialético não poderá ser apenas teórico, mas também terá que se proceder segundo o silogismo prático. Não parece que Lima Vaz tenha pensado nessas consequências, em todo caso estas se impõem ao leitor atento e ao filósofo desejoso do restabelecimento da unidade do ético e do político na assim chamada pós-modernidade.

\section{Fontes}

LIMA VAZ, H. C. DE. Antropologia filosófica I. Curso ministrado junto à Graduação em Filosofia do ISI-CES, primeiro semestre de 1985, Manuscrito. Memorial Pe. Vaz. Ficha 40, Arm. Fotocópia. Material disponibilizado ao autor em 2018.

LIMA VAZ, H. C. DE. Antropologia filosófica. Curso ministrado junto à Graduação em Filosofia da UFMG, segundo semestre de 1968, Transcrição de gravações e notas de aula de José Maria Moreira e Maria Eugenia. Memorial Pe. Vaz. Ficha 90, Armário 3, Gaveta 5. Fotocópia. Material disponibilizado ao autor em 2018.

LIMA VAZ, H. C. DE. A teoria hegeliana do conceito. Curso ministrado junto ao Mestrado em Filosofia da UFMG, primeiro semestre de 1977, Caderno de anotações de H. C. de Lima Vaz. Memorial Pe. Vaz. Ficha 11, Armário 1, Gaveta 5. Fotocópia. Material disponibilizado ao autor em 2013. 
LIMA VAZ, H. C. DE. A Enciclopédia de Hegel. Curso ministrado junto ao Mestrado em Filosofia da UFMG, 1974, Transcrição dos áudios dos cursos de H. C. de Lima Vaz. Memorial Pe. Vaz. Fita 64B. Cópia. Material disponibilizado ao autor em 2013.

\section{Referências bibliográficas}

ARISTOTE, L'Éthique a Nicomaque. Introduction, traduction et commentaire par René Antoine Gauthier et Jean Yves Jolif. Deuxième édition avec une introduction nouvelle. Louvain: Publications Universitaires; Paris: Bëatrice-Nauwelaerts, 1970.

HEGEL, G. W. F. Werke. Auf der Grundlage der Werke von 1832-1845 neu edierte Ausgabe. Redaktion Eva Moldenhauer und Karl Markus Michel. Frankfurt am Main: Suhrkamp Verlag, 1969-1971.

Wissenschaft der Logik, II, Werke 6, 1969.

Grundlinien der Philosophie des Rechts, Werke 7, 1970.

Enzyklopädie, I. Die Wissenschaft der Logik, Werke 8, 1970.

Enzyklopädie, II. Die Naturphilosophie, Werke 9, 1970.

Enzyklopädie, III. Die Philosophie des Geistes, Werke 10, 1970.

H. C. DE. LIMA VAZ, Método e dialética, in E. F. DE BRITO; L. H. CHANG. Filosofia e método. São Paulo: Loyola, 2002,

LIMA VAZ, H. C. DE. Escritos de Filosofia VI. Ontologia e história. São Paulo: Loyola, 2001.

LIMA VAZ, H. C. DE. Escritos de Filosofia V. Introdução à Ética filosófica II, São Paulo: Loyola, 2000.

LIMA VAZ, H. C. DE. Escritos de Filosofia IV. Introdução à Ética filosófica 1. São Paulo: Loyola, 1999.

LIMA VAZ, H. C. DE. Antropologia Filosófica I, São Paulo: Loyola, 1991.

LIMA VAZ, H. C. DE. Escritos de Filosofia II. Ética e Cultura, São Paulo: Loyola, 1988.

SILVA, M. M. DA. Introdução ao problema da fundamentação especificamente filosófica do Direito contemporâneo. In Revista Guairacá, 21, (2005): 103-125.

Endereço do Autor:

Rua Renato Guimarães Pupo, 135

Núcleo Santa Cruz

Bairro Boqueirão

85022-350 Guarapuava - PR

immanuelmoreyra@gmail.com 